\title{
РЕЗУЛЬТАТИ МОРФОЛОГІЧНОГО, ЧАСОВОГО ТА СПЕКТРАЛЬНОГО АНАЛІЗУ АРТЕРІАЛЬНИХ ОСЦИЛОГРАМ ХВОРИХ НА ЦУКРОВИЙ ДІАБЕТ
}

\author{
Д. В. Вакуленко, Л. О. Вакуленко, \\ О. В. Кутакова ${ }^{1}$, В. В. Лесів ${ }^{2}$ \\ ДВНЗ «Тернопільський державний медичний університет \\ імені І. Я. Горбачевського МОЗ України» \\ ${ }^{1}$ Комунальна установа «Центральна районна лікарня» Житомирської районної ради \\ ${ }^{2}$ Тернопільський національний технічний університет ім. І. Пулюя
}

\begin{abstract}
Морфологічний, часовий, спектральний аналіз артеріальних осцилограм засвідчив, що хворим на цукровий діабет притаманне порушення співвідношення активності обох ланок вегетативної нервової системи (достовірне зростання активності симпатичної ланки з незначним - парасимпатичної), зниження збудливості судинної стінки під час компресії плеча манжеткою, порушення координації між місцевими саморегуляторними механізмами та центральною нейрогуморальною регуляцією діяльності серцево-судинної системи, зниження активності вазомоторного центру та пружно-еластичних властивостей судинної стінки. Показники AMo, IN, IVR, BP, RMSSD осцилограм залежать від пружно-еластичних властивостей судинної стінки. Використання морфологічного, часового та спектрального аналізу артеріальних осцилограм хворих на цукровий діабет допоможе лікарю більш ефективно спланувати профрілактичний, діагностичний, терапевтичний процес.
\end{abstract}

Ключові слова: морфологічний, часовий, спектральний аналіз артеріальних осцилограм, цукровий діабет.

\section{RESULTS OF MORPHOLOGICAL, TEMPORAL AND SPECTRAL ANALYSIS OF ARTERIAL OSCILLOGRAMS OF PATIENTS WITH DIABETES MELLITUS}

\author{
D. V. Vakulenko, L. O. Vakulenko, \\ O. V. Kutakova ${ }^{1}$, V. V. Lesiv ${ }^{2}$

\begin{abstract}
SHEI "I. Ya. Gorbachevsky Ternopil state medical university of MH of Ukraine"
${ }^{1}$ Municipal institution «Central District Hospital» Zhytomyr District Council

2. Pul'uj Ternopil National Technical University
\end{abstract}

\begin{abstract}
The morphological, temporal, and spectral analysis of arterial oscillograms has shown that patients with diabetes mellitus have an inherent disruption of the vegetative nervous system activity (a significant increase of sympathetic part activity with a negligible increase of parasympathetic part activity); reduction of vascular wall excitability during cuff arm compression, disturbance of coordination in local self-regulating mechanisms and central neurohumoral regulation of cardiovascular system activity, decrease of vasomotor centre activity and elastic properties of the vascular wall. Oscillograms indicators AMo, IN, IVR, BP, RMSSD depend on the elastic properties of the vascular wall. The use of morphological, temporal and spectral analysis of arterial oscillograms in patients with diabetes mellitus will help physician more effectively plan a preventive, diagnostic, and therapeutic process.
\end{abstract}

Key words: morphological, temporal, spectral analysis of arterial oscillograms, diabetes mellitus. 


\title{
РЕЗУЛЬТАТЫ МОРФОЛОГИЧЕСКОГО, ВРЕМЕННОГО И СПЕКТРАЛЬНОГО АНАЛИЗА АРТЕРИАЛЬНЫХ ОСЦИЛЛОГРАММ БОЛЬНЫХ САХАРНЫМ ДИАБЕТОМ
}

\author{
ГВУЗ «Тернопольский государственный медицинский университет \\ имени И. Я. Горбачевского МЗ Украины» \\ ${ }^{1}$ Коммунальное учреждение «Центральная районная больница» \\ Житомирского районного совета \\ ${ }^{2}$ Тернопольский национальный технический университет им. И. Пулюя
}

Д. В. Вакуленко, Л. А. Вакуленко, А. В. Кутакова ${ }^{1}$, В. В. Лесив ${ }^{2}$

\begin{abstract}
Морфологический, временной, спектральный анализ артериальных осциллограмм свидетельствует о том, что при сахарном диабете нарушается соотношение активности обоих звеньев вегетативной нервной системы (достоверный рост активности симпатического звена и незначительный - парасимпатического); отмечается снижение возбудимости сосудистой стенки во время компрессии плеча манжетой, нарушение координации между местными саморегуляторными механизмами и центральной нейрогуморальной регуляцией деятельности сердечно-сосудистой системы, снижение активности вазомоторного центра и упруго-эластических свойств сосудистой стенки. Показатели AMo, IN, IVR, BP, RMSSD зависят от упруго-эластических свойств сосудистой стенки. Использование морфологического, временного, спектрального анализа артериальных осциллограмм больных сахарным диабетом поможет врачу более эфффективно планировать профилактический, диагностический, терапевтический процесс.
\end{abstract}

Ключевые слова: морфологический, временной, спектральный анализ артериальных осциллограмм, сахарный диабет.

Вступ. «Неінфекційна епідемія ХХІ століття» - цукровий діабет (ЦД) - затягнула у свій вир в Україні понад 1,3 млн хворих, з яких понад 212134 потребують щоденних ін'єкцій інсуліну (МО3 України, 2013). Назріла необхідність удосконалення сучасних інформаційних технологій для раннього виявлення донозологічних і преморбідних станів та резервних можливостей організму хворих на ЦД. Застосування артеріальної осцилографії, як дешевого неінвазивного об’єктивного методу оцінки стану гемодинаміки у хворих на ЦД, допоможе лікарю більш ефективно спланувати профілактичний, діагностичний, терапевтичний процес. Зареєструвати артеріальну осцилограму (AО) можна під час вимірювання артеріального тиску (прилад ВАТ41-2). Подальший аналіз її проводиться за допомогою запропонованих авторами спеціальних комп’ютерних програм [3].

Мета дослідження: вивчити й оцінити стан гемодинаміки у хворих на ЦД за допомогою морфологічного, часового, спектрального аналізу АО та сформувати діагностичні маркери для раннього виявлення ризиків виникнення захворювання, оцінки ефективності лікування.

Матеріали та методи дослідження. Нами обстежено 169 осіб. 3 них 61 хворий на ЦД (обох типів) віком 20-55 років - основна група. До складу контрольної групи ввійшло 6 здорових осіб віком 20-25 років. Усім обстеженим реєстрували $\mathrm{AO}$, які були піддані морфологічному, часовому, спектральному, кластерному аналізу. У 23 хворих на ЦД зареєстровано також електрокардіограми (ЕКГ), з подальшим аналізом варіабельності серцевого ритму (ВСР), які порівняли з результатами аналогічного обстеження 25 здорових осіб. Для контролю використано АО 68 здорових осіб, зареєстрованих нами до та після фізіологічного стресу (проби Руф’є). При часовому та спектральному аналізі скористалися методами, що застосовують при аналізі ВСР електрокардіосигналу [2, 8, 9]

Результати та їх обговорення. Морфологічний аналіз АО. Для морфологічного аналізу АО використано 9 критеріїв, кожен з яких (в порядку зростання відхилень від прийнятої нами норми) оцінено за шкалою від 1 до 5 балів. Кількісній оцінці підлягали динаміка зростання та спадання амплітуди осциляцій на початку компресії плеча манжетою (M-1) та від досягнення діастолічного тиску і до завершення компресії (M-2); наявність порушень ритмічності осциляцій (М-3); кількість максимальних за амплітудою осциляцій - у фазі максимальної компресії плеча під час діастоли (M-4); форми верхніх екстремумів осциляцій на початку компресії (M-5); наявність дрібних осциляцій на початку компресії 


\section{Порівняльна характеристика критеріїв морфологічного аналізу АО здорових осіб та хворих на ЦД}

\begin{tabular}{|c|c|c|c|}
\hline Критерій & Здорові $(\mathrm{n}=68)$ & Хворі на ЦД $(\mathrm{n}=61)$ & P \\
\hline $\mathbf{M}-\mathbf{M} \pm \mathrm{m}$ & $\mathbf{4 , 1 5} \pm \mathbf{0 , 2 1}$ & $\mathbf{3 , 0 2} \pm \mathbf{0 , 1 6}$ & $<0,001$ \\
\hline $\mathbf{M}-2$ & $\mathbf{2 , 8 9} \pm \mathbf{0 , 3 6}$ & $\mathbf{2 , 1 2} \pm \mathbf{0 , 1 7}$ & $<0,001$ \\
\hline $\mathbf{M}-3$ & $\mathbf{2 , 5 5} \pm \mathbf{0 , 4 7}$ & $\mathbf{1 , 5 9} \pm \mathbf{0 , 1 8}$ & $<0,001$ \\
\hline M-4 & $2,60 \pm 0,16$ & $3,59 \pm 0,09$ & $<0,001$ \\
\hline M-5 & $1,79 \pm 0,22$ & $2,49 \pm 0,14$ & $<0,05$ \\
\hline $\mathbf{M}-\mathbf{M}$ & $\mathbf{1 , 7 7} \pm \mathbf{0 , 1 7}$ & $\mathbf{1 , 5 2} \pm \mathbf{0 , 1 1}$ & $<0,001$ \\
\hline M-7 & $\mathbf{2 , 2 4} \pm \mathbf{0 , 3 6}$ & $\mathbf{1 , 2 6} \pm \mathbf{0 , 0 9}$ & $<0,001$ \\
\hline M-8 & $3,80 \pm 0,21$ & $4,15 \pm 0,34$ & $<0,001$ \\
\hline M-9 & $3,69 \pm 0,17$ & $4,92 \pm 0,08$ & $<0,001$ \\
\hline
\end{tabular}

(М-6); кількість екстремальних осциляцій (М-7); динаміка зміни площі висхідної частини осциляцій (М-8); динаміка зміни площі низхідної частини осциляцій (М-9) [3].

Результати морфологічного аналізу АО хворих на ЦД та здорових осіб представлені у табл. 1.

Як видно з табл. 1, усі досліджувані показники достовірно відрізнялися, хоча мали різнонаправлену динаміку. Так, значення показників М-1, M-2, M-3, M-6, М-7 знижувалися, це може свідчити про сповільнення термінової реакції судинної стінки на наростання компресії, що зумовлене нервоворефлекторними механізмами регуляції артеріального тиску [6] і є результатом порушення стану координації між місцевими саморегуляторними механізмами та центральною нейрогуморальною регуляцією діяльності серцево-судинної системи (CСC) [5]. Значення показників M-4, M-5, М-8, M-9 зростали. Показник M-4 зумовлений радіальним розширенням судинної стінки під час систоли. Значне збільшення кількості осциляцій з максимальною амплітудою в процесі зростання компресії свідчить про зростання ступеню пасивного розтягнення судин під час систоли, що зумовлено зниженням пружно-еластичних властивостей судинної стінки [7]. Збільшення значень двох останніх показників $€$ результатом утруднення проштовхування крові в периферійні судини і $€$ свідченням порушення стану координації місцевих саморегуляторних механізмів та центральної нейрогуморальної регуляції діяльності ССС [4-7].

Часовий аналіз. Дослідження показників часового аналізу та варіаційної пульсометрії дали можливість дійти таких висновків: обстеженим нами хворим притаманне достовірне зниження (порівняно із здоровими особами) значень показників pNN50, Mo, SDSD та зростання частоти серцевих скорочень, VPR, HVR-індексу. Указана динаміка свідчить про зростання активності симпатичної ланки вегетативної нервової системи (ВНС) та підвищення ролі центрального контуру в діяльності ССС у хворих на ЦД. Отримана динаміка досліджуваних показників АО відповідає даним інших авторів, отриманих при аналізі ВСР електрокардіосигналу у хворих на ЦД $[1,2,6]$.

Проте зниження значень показників AMo, IN, IVR та зростання варіаційного розмаху АО у хворих на ЦД $(\mathrm{P}<0,05)$ свідчить (за аналогією з ВСР при аналізі ЕКГ) про збереження (навіть незначне зростання) активності парасимпатичної (ПС) ланки ВНС. Отримані дані співпадають з напрямком динаміки їх за АО здорових осіб, що були зареєстровані після проби Руф’є (табл. 2).

Аналіз представлених результатів АО дає можливість пов’язати указану динаміку з пружно-еластичними властивостями судинної стінки і віднести їх до специфічних показників, що характеризують стан судин. Адже симпатичні та парасимпатичні нерви окрім хроно- та інотропного впливу на міокард забезпечують регуляцію судинного тонусу (Баєвський Р. М.) [2].

Привертає до себе увагу не лише відсутність зниження, але і незначне зростання RMSSD (c) у хворих на ЦД, яке не відповідає навіть динаміці у здорових осіб на пробу Руф’є (табл. 2). Водночас, підвищення RMSSD реєструвалося у хворих на ЦД і за показниками ЕKГ. RMSSD — міра потужності високочастотних нейрогуморальних впливів, 
Показники часового аналізу АО, що свідчать про зростання активності ПС-ланки ВНС у Хворих на ЦД та у здорових осіб після проби Руф’є

\begin{tabular}{|c|c|c|c|}
\hline \multirow{2}{*}{ Показник } & \multirow{2}{*}{$\begin{array}{c}\text { Хворі на ЦД } \\
(\mathrm{n}=51)\end{array}$} & До проби Руф’ $\epsilon$ & Після проби Руф’ $\epsilon$ \\
\cline { 2 - 4 } & $44,290 \pm 1,969^{*}$ & $48,070 \pm 1,363$ & $31,010 \pm 1,354$ \\
\hline AMо (\%) & $63,830 \pm 5,720^{*}$ & $148,300 \pm 10,539$ & $42,350 \pm 10,333$ \\
\hline IN (у. о) & $125,173 \pm 0,030^{*}$ & $260,700 \pm 15,694$ & $95,740 \pm 15,412$ \\
\hline IVR (у. o) & $0,400 \pm 0,027 *$ & $0,290 \pm 0,008$ & $0,440 \pm 0,008$ \\
\hline BP (у. o) & $0,108 \pm 0,070$ & $0,142 \pm 0,008$ & $0,125 \pm 0,008$ \\
\hline RMSSD (c) &
\end{tabular}

Примітка. - д достовірні зміни відносно показників здорових

показник активності ПС-ланки ВНС. І. В. Бабунц (2002) вважає, що показник RMSSD ЕКГ більш інформативний, ніж показники рNN50 (\%) та NN50, бо має кращі статистичні властивості. Не виключено, що RMSSD осцилограм в процесі подальших досліджень можна буде використовувати як маркер стану хворих при ЦД [1].

Спектральний аналіз. Порівняння показників спектрального аналізу АО (рис. 1) між обстеженими нами здоровими особами та хворими на ЦД засвідчило наступне.

У хворих на ЦД спостерігається зростання (на 39,1 \%) загальної потужності спектру нейрогуморальної модуляції (ТРмс²), що відображає сумарний ефект впливу на стан кровообігу усіх рівнів регуляції в діапазоні частот $\leq 0,4$ Гц. При цьому на $24 \%(\mathrm{P}<0,05)$ зріс відсоток ULF - міри потужності ультранизькочастотних впливів нейрогуморальної регуляції. Водночас, на 3,8 \% зменшився відсоток потужності спектру VLF - повільних хвиль другого порядку, які відображають активність центральних ерготропних і гуморально-метаболічних механізмів регуляції гемодинаміки і характеризують вплив вищих вегетативних центрів на серцево-судинний підкорковий центр. Найбільше (на 44 \%, Р < 0,05) зменшився відсоток LF (вазомоторних) хвиль, які відображають активність центрів довгастого мозку - кардіостимулюючого і судиннорухового (вазомоторного). Водночас, на 9,4 \% зріс відсоток потужності дихальних хвиль (HF), який представлений стовбуровими структурами довгастого мозку і визначає активність автономного контуру регуляції діяльності ССС, за яку відповідає ПСвідділ ВНС [2] (рис. 1).

При аналізі літературних джерел щодо ВСР електрокардіосигналу у хворих на ЦД ряд авторів (Баєвський Р. М., Бабунц І. В., Воробйов К. П.) указують на різке зниження потужності хвиль 1-го порядку (LF) та дихальних хвиль (HF). Перший критерій підтверджується нашими дослідженнями, проте другий - не співпадає. Незначне зростання відсотку потужності дихальних хвиль, визначених нами при аналізі АО у хворих на ЦД, дає можливість передбачити вплив пружно-еластичних властивостей судинної стінки та рефлекторних (хемо- та барорецепторних) механізмів регуляції

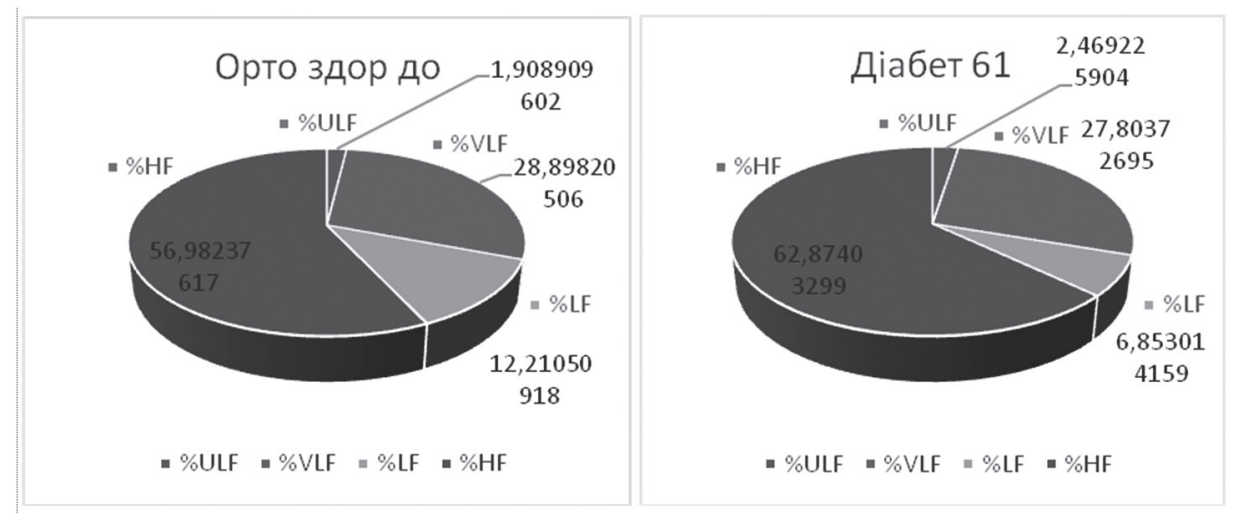

Рис. 1. Показники спектрального аналізу АО здорових осіб (зліва) і хворих на ЦД (справа) 
кровообігу, що включаються під час компресії плеча манжеткою в процесі вимірювання артеріального тиску та реєстрації АО. При цьому збудження хеморецепторів аорти і сонної артерії викликає судинні пресорні, а подразнення барорецепторів депресорні рефлекси $[4,10]$.

Коефіцієнт LF/HF зріс на 9,26 \pm 0,2 \%. На думку К. П. Воробйова, за показниками ВСР ЕКГ при напруженій і малоефективній програмі пристосувальних реакцій організму коефіцієнт LF/HF зростає [4].

Ритми мозку. Зареєстровано зниження відсоткового вмісту потужності \% Teta (на 29,0 \pm 1,2 \%) i \% Delta-хвиль - (на 3,03 \pm 0,13 \%) та зростання відсотку Alpha (на 63,0 \pm 4,2 \%) i Beta (на 88,0 \pm 3,7 \%). Зростання відсотку Delta- та Alpha-хвиль дає можливість пов’ язати їх активність з процесами, що відбуваються при розвитку і прогресуванні ЦД. Розвиток і прогресування захворювання пов'язані з розвитком трьох основних чинників: дисемінованої дегенерації дрібних нервових волокон обох відділів ВНС, що призводить до периферійної вегетативної недостатності; мікро- і макроангіопатій; дисметаболічного та токсичного пошкодження міокарду [2].
Побудова кореляційного портрету. Для побудови кореляційного портрету здорових осіб та хворих на ЦД відібрали показники, де коефіцієнт кореляції був у межах від 0,9 до 1 та від -0,9 до -1. Притаманним лише для хворих на ЦД виявлено пари позитивних корелят між ваговими значеннями Alpha (8-13 Гц) та Beta (14-25 Гц) осцилограми. Від’ємна кореляція виявлена між ваговими значеннями Delta та Alpha. Потужність спектру інтервальної оцінки HF корелювала $з$ вагою HF в загальному спектрі (0-0,4 Гц), що узгоджується зі зростанням значень вказаних показників за результатами часового аналізу.

Для формування достовірних меж з метою диференційної діагностики досліджуваних груп проведено відбір показників (серед 432), значення яких не перетинається в 90 \%, що для прикладу проілюстровано на рис. 2 за допомогою коробкових графіків досліджуваних вибірок.

Дослідження показали, що для хворих на ЦД потужність спектру за перетворенням Фур'є в діапазоні від 15 до 18 Гц в період досягнення максимальної амплітуди осциляцій може бути також маркером для диференційної діагностики при ЦД.

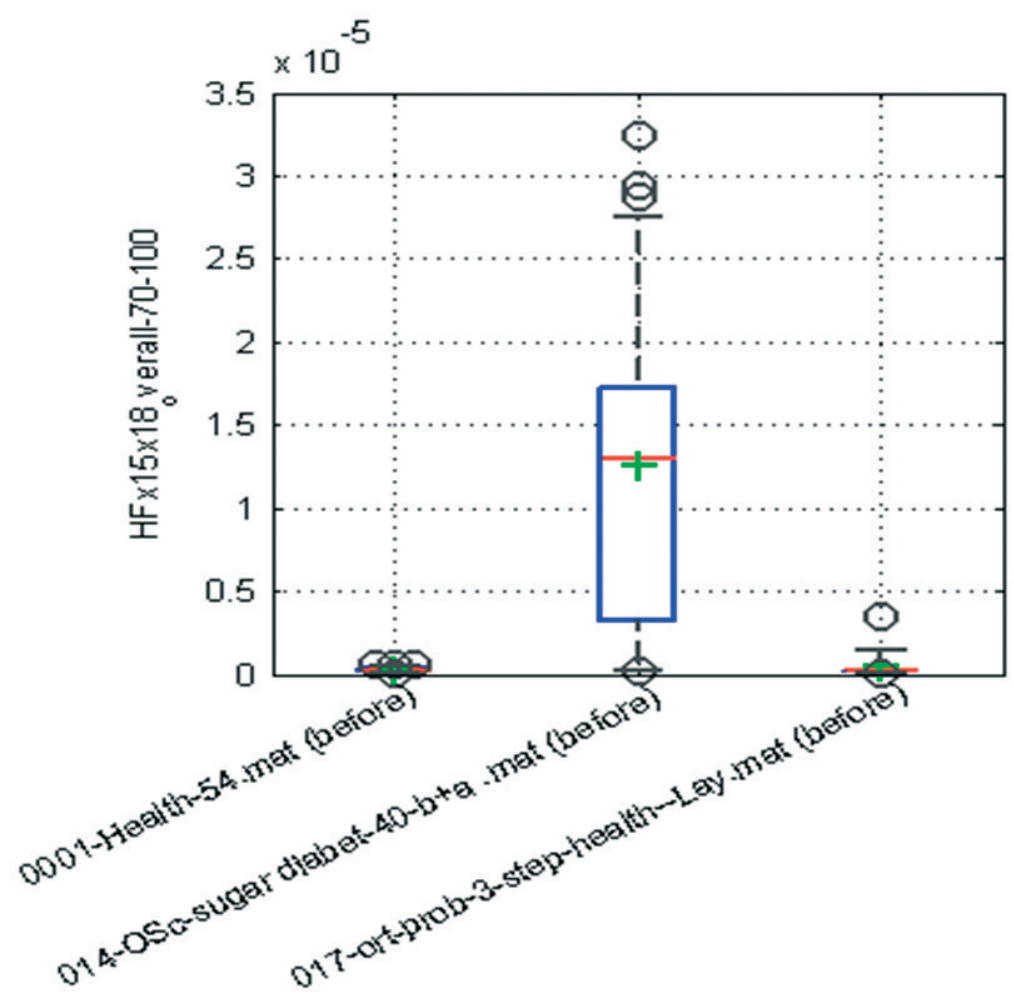

Рис. 2. Динаміка зміни показника НF (визначеного за перетворенням Фур’є) відображена за допомогою коробкових графіків. По порядку зліва направо: здорові особи в положенні сидячи, хворі на Цд та здорові особи в положенні лежачи 
Висновки. При морфологічному аналізі АО виявлено, що хворим на ЦД притаманне порушення співвідношення активності обох ланок ВНС, зниження збудливості судинної стінки під час компресії плеча, порушення координації між місцевими саморегуляторними механізмами та центральною нейрогуморальною регуляцією діяльності ССС, зниження пружно-еластичних властивостей судинної стінки.

Показники AMo, IN, IVR, BP, RMSSD осцилограм залежать від пружно-еластичних властивостей судинної стінки. Показник RMSSD можна віднести до специфічних показників, що характеризують стан судин у хворих на ЦД. Результати спектрального аналізу АО дають можливість зробити висновки, що у хворих на ЦД достовірно зростає активність нейрогуморальної регуляції і знижується активність вазомоторного центру, який регулює судинний тонус. Останній (LF) можна віднести до специфічних механізмів мобілізації функціональних резервів хворих на ЦД. При цьому зберігається активність парасимпатичної ланки BHC. Зростання відсотку Delta- та Alpha-хвиль дає можливість пов'язати їх активність зі змінами, що відбуваються в процесі розвитку і прогресування ЦД.

Вивчення морфологічного, часового та спектрального аналізу АО хворих на ЦД допоможе лікарю більш ефективно спланувати профілактичний, діагностичний, терапевтичний процес.

\section{Література.}

1. Бабунц И. В. Азбука анализа вариабельности сердечного ритма [Электронный ресурс] / И. В. Бабунц, 3. М. Мириджанян, Ю. А. Машаех. - Компакт-диск. Электронная версия книги. - Ставрополь, 2002.

2. Баевский Р. М. Оценка адаптационных возможностей организма и риск развития заболеваний / Р. М. Баевский, А. П. Берсенева. - М. : Медицина, 1997. - 265 с.

3. Вакуленко Д. В. Інформаційна система морфологічного, часового, частотного та кореляційного аналізу артеріальних осцилограм у фізичній реабілітації : монографія / Д. В. Вакуленко. - Тернопіль : ТДМУ, 2015. - 212 с.

4. Воробьев К. П. Теоретические основы использования параметров вариабельности сердечного ритма для оценки функционального состояния организма / К. П. Воробьев // Загальна патологія та патологічна фізіологія. - 2011. - Т. 6, № 4. - С. 68-97.

5. Комплекс аппаратно-программный неинвазивного исследования центральной гемодинамики методом объемной компрессионной осциллометрии КАП
ЦГ осм - «Глобус» : инструкция по применению. Белгород : Глобус, 2004. - 51 с.

6. Механика кровообращения / К. Каро, Т. Педли, Р. Шротер, У. Сид ; пер. С англ. - М. : Мир, 1981. -624 c.

7. Пат. № 2360596С РФ. Способ определения артериального давления, параметров гемодинамики и состояния сосудистой стенки с использованием осциллометрии высокого разрешения / Цупко И. В. заявитель и патентообладатель. - № 2008101946/14 ; заявл. 24.01.2008 ; опубл. 10.07.2009.

8. Смирнов К. Ю. Разработка и исследование методов математического моделирования и анализа биоэлектрических сигналов / К. Ю. Смирнов, Ю. А. Смирнов. - СПб. : Научно-исследовательская лаборатория «ДИНАМИКА», 2001. - 60 с.

9. Яблучанский Н. И. Вариабельность сердечного ритма в помощь практическому врачу / Н. И. Яблучанский, А. В. Мартыненко. - Харьков, 2010. - 131 с.

10. Safar M. E. Current perspective on arterial stiffness and pulse pressure in hypertension and cardiovascular disease / M. E. Safar, B. I. Levy, H. Struijker-Boudier // Circulation. - 2003. - Vol. 107, No. 22. - P. 2864-2869.

\section{References.}

1. Babunts, I. V., Miridzhanyan, Z. M., \& Mashaekh, Yu. A. (2002). Azbuka analiza variabel'nosti serdechnogo ritma [ABC of heart rate variability analysis]. [CD. E-book]. Stavropol'.

2. Baevskii, R. M., \& Berseneva, A. P. (1997). Otsenka adaptatsionnykh vozmozhnostei organizma i risk razvitiya zabolevanii [Assessment of adaptive capabilities of the body and the risk of developing diseases]. Moscow: Medicine.

3. Vakulenko, D. V. (2015). Informatsiina sistema morfologichnogo, chasovogo, chastotnogo ta korelyatsiinogo analizu arterial'nikh ostsilogram $\mathrm{u}$ fizichnii reabilitatsii [Information system of morphological, temporal, frequency and correlation analysis of arterial oscillograms in physical rehabilitation]: monography. Ternopil: TSMU.

4. Vorob’ev, K. P. (2011). Teoreticheskie osnovy ispol'zovaniya parametrov variabel'nosti serdechnogo ritma dlya otsenki funktsional'nogo sostoyaniya organizma [Theoretical bases of the use of parameters of heart rate variability for an estimation of a functional state of an organism]. Zagal'na patologiya ta patologichna fiziologiya (General pathology and pathological physiology), 6(4), 68-97.

5. Kompleks apparatno-programmnyi neinvazivnogo issledovaniya tsentral'noi gemodinamiki metodom ob»emnoi kompressionnoi ostsillometrii KAP TsG osm - «Globus» [Hardware-software complex for noninvasive study of central hemodynamics by the method of volumetric compression oscillometry APC CH osm - «Globus»]. Instruction. (2004). Belgorod: Globus. 
6. Caro, C. G. Pedley, T. J., Schroter, R. C., \& Seed, W. A. (1981). The mechanics of the circulation. Moscow: Mir.

7. Tsupko, I. V (2009). Sposob opredeleniya arterial'nogo davleniya, parametrov gemodinamiki i sostoyaniya sosudistoi stenki s ispol'zovaniem ostsillometrii vysokogo razresheniya [The method for determining blood pressure, hemodynamic parameters and the state of the vascular wall using high-resolution oscillometry]. Patent RF No. 2360596.

8. Smirnov, K. Yu., Smirnov, Yu. A. (2001). Razrabotka i issledovanie metodov matematicheskogo modelirovaniya i analiza bioelektricheskikh signalov [Development and research of methods of mathematical modeling and analysis of bioelectric signals]. St. Petersburg: research laboratory «DYNAMYKA».

9. Yabluchanskii, N. I., Martynenko, A. V. (2010). Variabel'nost' serdechnogo ritma v pomoshch' prakticheskomu vrachu [Heart rate variability to help a practical doctor]. Khar'kov.

10. Safar, M. E., Levy, B. I., \& Struijker-Boudier, H. (2003). Current perspective on arterial stiffness and pulse pressure in hypertension and cardiovascular disease. Circulation, 107(22), 2864-2869. 